\title{
Construction and Implementation of Teaching Mode for Literature Retrieval Based on "Flipped Classroom"
}

\author{
Haijing Qi ${ }^{1, a}$ and Xiang Liu", ${ }^{1}$ * \\ ${ }^{1}$ Library, Beihua University, Jilin, China \\ a499078596@qq.com, ${ }^{b} 461773846 @ q q . c o m$ \\ * corresponding author
}

Keywords: Flipped classroom; Literature retrieval; FCM; Supporting system

\begin{abstract}
Objective: Based on the teaching experience of literature retrieval and the advantaged idea of integration of information technology and curriculum and flipped classroom, the teaching model of the flipped classroom is formulated, the platform of flipped classroom is designed, in order to promote the effectiveness of teaching and learning. Methods: The study takes "literature retrieval" as an example, the implementation of the FCM process in a flipped classroom with a teaching example is elaborated and a comparative analysis is done. Results: Through the research of theory and practice, we found that the effect of FCM were Obvious. Conclusion: Most of the students are willing to continue to practice the FCM, but there are some problems should be solved.
\end{abstract}

\section{Introduction}

Flipped Classroom Model is known as "FCM" for short. The basic idea is to flip the traditional teaching process over, students learn knowledge by watching video, consulting materials, online communication and so on; teachers use more time to communicate with students, organize group activities, answer the questions and so on[1-2]. Practice shows that flipped classroom has a positive influence on the stimulating students' interests, raising test scores and so on[3-4].

\section{Research background}

Research on foreign FCM applications. The concept of FCM has been proposed since 2007, Many foreign experts and scholars have made intensive study on the FCM applications. Italian scholar Marco Ronchetti studied the video on-Line as re-placement of old teaching practice[5]. FCM practical research on collaboration ability, innovation ability and task orientation has been carried out by Jeremv F. Strayer of American educational technology specialist[6]; The course of "data structure" has been used by flipped classroom in the department of computer science and systems analysis in Miami University[7]; The course of "statics" has been used by flipped classroom in the University of Puerto Rico[8]; a series of courses of MOOC have been published in JOHNS HOPKINS University [9].

Research on domestic FCM applications. The flipped classroom teaching model is applied to the library entry education and information literacy course in Chongqing University[10] and East China Normal University[11]; Zhu Weili[12] and Xiao Dan[13] respectively explored the course design based on the environment of "flipped classroom" and "MOOC";Zhang Dan[14] proposed to make independent information literacy MOOC and develop embedded Mini MOOC, it enriches the content of information literacy course; Wang Haiying[15] tried to set up a micro course for digital resources education in university library; Jiang Lili[16] has put forward the theoretical framework design of flipped classroom of information literacy in the university library.

The FCM construction of literature retrieval

At present, the course of literature retrieval is divided into theory and practice contents, Among them, more attention is paid to the practical link of students. Based on the advantages of "flipped classroom" and the advanced experience of information technology and teaching integration, in this paper, literature retrieval FCM has been structured, as shown in Figure 1. 


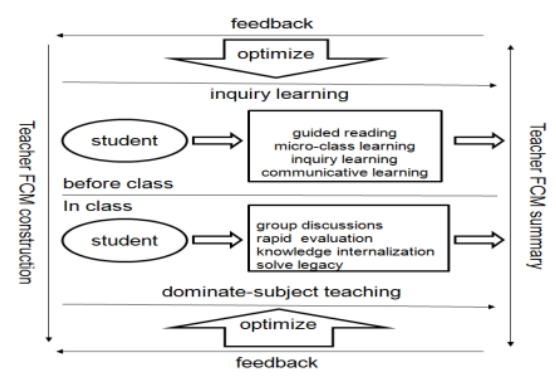

Figure 1. Construction of Literature Retrieval FCM

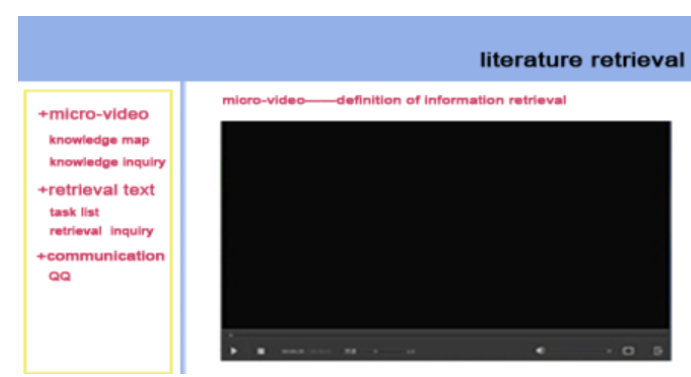

Figure 2. FCM system

First, teacher needs to construct literature retrieval FCM. Teachers should think the links before, in and after class, do a good job of formative assessment and summative assessment and so on; secondly, before class, teachers need to monitor students' learning of literature retrieval, communicate and interact with each other, do a good job of formative evaluation before class, students need to use self-inquiry learning before class; third, in class, this part mainly applies the thought of "dominate-subject teaching" mode, in the process, teachers can communicate with students appropriately, do a good job in the formative assessment in class; at last, teacher should do a good job in the summary of literature retrieval FCM.

\section{Design of FCM Learning Support System}

In order to better practice research of FCM , The author tried to design the FCM learning support system, the interface of system is shown in Figure 2. In the initial stage of design, learning support system mainly includes micro video, retrieval testing and communication module.FCM learning support system mainly includes two functional support: self-learning and self-researching.

Self-learning. Self-learning emphasizes the active construction of knowledge, we should think the quality of students' learning, also we can't frustrate students' confidence and interest. The effectiveness of the resource allocation determines the quality of the platform function design. Micro-video provides us with a new idea, micro-video is a explaining of teaching or learning section or an activity process video which can help students to learn a basic knowledge (or knowledge fragments, aspects), or a problem (task) to solve ideas and methods, the related materials should include the guidance case (task list), development materials and so on. The types of micro-video are diverse, mainly: teaching type, demonstration type, inquiry type, experimental type and so on. Each type has a unique advantage, it requires reasonable recording, editing, processing, and configuration into the knowledge map of the learning support system. It requires reasonable recording, editing, processing, and configuration into the knowledge map of the learning support system. Knowledge map is an important tool to guide students to learn independently, it is in accordance with the syllabus, teaching links, knowledge points and other content of combing to get. Independent learning resources include animation tools, e-learning materials and so on.

Self-researching. While students actively construct knowledge, self-researching link is particularly important, this function mainly includes operation inquiry, subject inquiry, task inquiry and so on. Operation inquiry mainly includes specific database retrieval and operation exercises, combining the database of library; subject inquiry can enable students to enter the deep stage of inquiry, learning support system set the subject of inquiry for a research topic, the contents of each subject include ideas of inquiry, reference conclusions and so on, students can select and switch each field according to the idea of inquiry, can complete various combination of Boolean logical relation, also can carry out independent inquiry; task inquiry is based on the task list set in the FCM learning support system, enable students to carry out independent inquiry under the driving of the task list content, completing the task and solving the problems to complete the inquiry process.

\section{Implementation Case of Literature Retrieval FCM}

In practice research part, we take Superstar Digital Library as a case. Because of the situation of literature retrieval teaching, there are some difficulties in implementing FCM,I arranged the time 
properly, by random cluster sampling, 50 students were selected as the experimental class members, class members include arts and science students, compared with regular classes, the number and profession are more consistent. Before class, I gave them a basic introduction to the flipped classroom teaching model, then organized the implementation of teaching.

The implementation process reference plan, implementation, observation, reflection and other links which are in action research method. Finally, the whole practice research process is divided into four parts: the teaching design plan link, the implementation link, the evaluation link, the reflection link and so on.

Scheme of Teaching Design. The second supporting link of FCM is classroom link, it's also particularly important. I have constructed the FCM teaching design scheme of Superstar Digital Library. Before class, student should complete the self-regulated learning of the relevant content of Superstar Digital Library by applying the learning support system within a week, the main contents include e-book database, mobile library, superstar learning, online reading and downloading of e-book and so on. According to the situation of self-regulated learning, the feedback of learning content and the problems in the application of learning support system are discussed. In class, according to the problems of students in the learning process and the outstanding problems in the operation of Superstar Digital Library, I will focus on the difficult and main points, the teams are under the leadership of the team leader, The team members learn the database by inquiry learning, The database include: Superstar Digital Library, mobile library, Duxiudatabase and so on. Students can choose autonomous learning, collaborative learning and task driven learning methods to further study and explore, and try to solve their own problems in groups. After class, students should record learning experience, share learning experience and the learning support system requirements and so on by using the learning support system communication module.

Implementation Link. One week before the class, FCM QQ group were set up and students were organized to join, make students know and understand the basic situation of FCM, know exactly the learning content, target and so on, then students downloaded and installed Chaoxing Xuexitong and established network discussion group and so on. Teachers and students followed the content and steps of the teaching design to complete and finish the study before class.

In class, according to the students' learning situation and feedback information ofSuperstar Digital Librarybefore class, I divided 50 students into 10 groups, identify the group leader. First,taking approximately 10 minutes, focusing on the common issues of feedback, common misgivings, combining important and difficult to explain, tried to solve their outstanding common problems. At this time, some students still had minor problems unsolved, for example, how to make electronic reading notes in Superstar Digital Library and so on. In order to solve such similar problems, the next, taking approximately 30 minutes, we organized students to work in groups. Due to the large number of students, it is very difficult to carry out individualized tutoring in a short time, the team leader can guide the team members in collaborative learning. At the same time, set the appropriate retrieval task list, guided each group to the cooperate learning and the task-driven study mode, then carried through a deep research.

After class, students used learning support system communication module to record their learning experience. They shared their learning experiences with each other, teachers and students participated in the depth analysis of the needs of the learning support system. The teacher completed the whole research process, the teacher completed a summative evaluation of the whole FCM process.

Evaluation Link. According to the FCM evaluation link, author designed an effective questionnaire, students' view were collected by using the questionnaires of questionnaire. The questionnaire were divided into subjective and objective questions. The research findings of objective questions are shown in Figure 3, Figure4, and Figure5. 


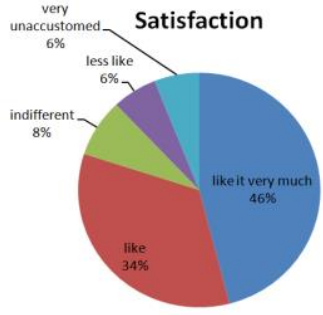

Figure 3. First question

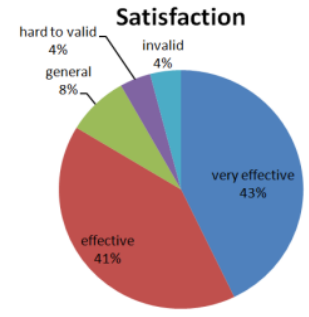

Figure 4. Second question

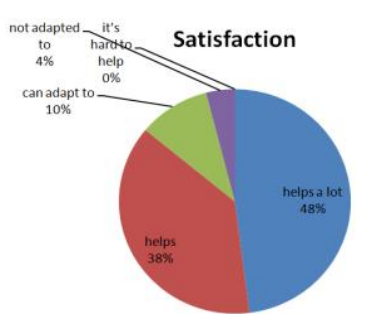

Figure 5. Third question

Research findings showed: the implementation of FCM in the experimental class has achieved good results, the effect is significant especially in learning interest, coordination and other aspects. Most of the students have an approved and satisfied attitude towards FCM, however, a few students also have low interest in the FCM learning, because of the poor adaptation of computer operation and FCM and so on. The advantages of FCM in students' learning are obvious, as shown in table 1.

Table 1. Comparison of students' learning

\begin{tabular}{|l|l|l|}
\hline \multicolumn{2}{|c|}{ FCM } & \multicolumn{1}{c|}{ Traditional mode } \\
\hline \multirow{3}{*}{$\begin{array}{l}\text { Students' } \\
\text { learning }\end{array}$} & Self-learning & Passive participation \\
\cline { 2 - 3 } & Meet individual needs & Hard to satisfy \\
\cline { 2 - 3 } & $\begin{array}{l}\text { Meet the needs of students' database } \\
\text { mining depth }\end{array}$ & Hard to satisfy \\
\cline { 2 - 3 } & Time and space for study are not limited & Learning time and space are limited \\
\cline { 2 - 3 } & Share rich learning resources & Restricted learning resources \\
\cline { 2 - 3 } & Meet online test requirements & Test demand Limited \\
\hline
\end{tabular}

Reflection link. Through the monitoring of the FCM whole process of the students' learning, it is found that there are still some bottlenecks and problems to be solved in the practice process.

There are Some Limitations in Learning Content Support of FCM. FCM is easy to implement task driven, the content of independent inquiry learning is remarkable. For example, we build an e-book task list in Superstar Digital Library, students complete autonomous learning according to the task list. However, the traditional model is more suitable for reasoning problems and logical relations of learning content.

FCM Adaptability Needs to be Improved. FCM theory and practice research are not accomplished overnight, not all of them will be good and effective. Some students are not adapted to the FCM model, the main reason is that learning support system is not perfect, self-learning can't be effectively supported, on the other hand, students are accustomed to the traditional teaching mode, it's hard to change the old way of studying at one time, this process should takes a lot of time, what's more, teachers need to spend more time on overall consideration, to build a more adaptable FCM.

The System Needs to be Perfected. The learning support system is currently in the design and testing phase. There is no complete, substantial and adaptable learning support system, many functional modules and details need to be improved and updated and need further improvement.

\section{Conclusion}

The results of this study show that: the advantage of FCM's new teaching model is obvious, but there are also shortcomings. The next step we will select the right time, space and environment for more in-depth theoretical and practical research, from design to practice, revise and upgrade the original design and mode, this process requires repeated thought and research. It is believed that this research will promote the integration of information technology and university teaching, renewing traditional teaching idea, it provides some theoretical reference and experience for the innovative attempt of FCM in Colleges and universities.

\section{Acknowledgements}

This paper is the relevant research result of the project of the 13th Five-year Plan of Educational Science in Jilin Province "Research on the effectiveness of SPOC flipped classroom teaching model of literature retrieval"(project number: GH170052) 


\section{Reference}

[1]Information on http://www.thedailyriff.com/articles/how-the-flipped-classroom-is-radicallytransforming-learning-536.php. (In Chinese)

[2]Information on http://www. knewton.com/flipped-classroom/.(In Chinese)

[3]Information on http://class-roomwindow.com/flipped-classrooms-improved-test-scores-andteacher-satisfaction/.(In Chinese)

[4]Information on http://www.jukui.com/.(In Chinese)

[5]Marco Renchetti: TECH-EDUCATION.(2010)No73,p.134-140.

[6]Jeremy F. Strayer. Learning Environ Res.(2012)No15,p.171-193.

[7][8]C.Y. He, Y.F. Ou, and Q. Cao: Research in Higher Education of Engineering, (2014) No.2,p.148-151+161. (In Chinese)

[9]Information on https://www.coursera.org/specializations/jhu-data-science.(In Chinese)

[10]J.R. Qin: The Library Journal of Henan,Vol:34 (2014) No.5,p.90-92 . (In Chinese)

[11]R.H. Huang and B.Y. Li: Documentation, Information \& Knowledge,(2015)No.4, p.12-21. (In Chinese)

[12]W.L. Zhu: Library Journal,(2013)No.4,p.87-90. (In Chinese)

[13]D. Xiao: Hebei Library Journal of Science and Technology, Vol:27(2014)No.2, p.94-96. (In Chinese)

[14]D. Zhang: The Library Journal of Henan,Vol:35(2015)No.2,p.69-70. (In Chinese)

[15]H.Y. Wang: Lantai World,(2015)No.5,p.52-53. (In Chinese)

[16]L.L. Jiang and Y.H. Chen: Library Journal,Vol:34(2015)No.12,p.23-28. (In Chinese) 